\title{
Lung resection after pneumonectomy: is it worth the risk?
}

\author{
Jan Van Slambrouck ${ }^{1,2} \wedge$, Laurens J. Ceulemans ${ }^{1,2 \wedge}$ \\ ${ }^{1}$ Laboratory of Respiratory Diseases and Thoracic Surgery (BREATHE), Department CHROMETA, KU Leuven, Leuven, Belgium; ${ }^{2}$ Department of \\ Thoracic Surgery, University Hospitals Leuven, Leuven, Belgium \\ Correspondence to: Laurens J. Ceulemans, MD, PhD. Laboratory of Respiratory Diseases and Thoracic Surgery (BREATHE), Department CHROMETA, \\ KU Leuven, Herestraat 49 O\&N 1 box 706, B-3000 Leuven, Belgium. Email: Laurens.ceulemans@uzleuven.be.
}

Received: 06 July 2020; Accepted: 13 August 2020; Published: 10 April 2021.

doi: $10.21037 /$ shc-20-75

View this article at: http://dx.doi.org/10.21037/shc-20-75

\section{Introduction}

According to the National Cancer Database between 2004 and 2013, pneumonectomy for non-small cell lung cancer (NSCLC) $(\mathrm{n}=79,953$ patients) accounted for 5 percent of all resections (1). After successful treatment however, patients remain at risk (1-5\%) for developing malignant lesions (recurrence or second primary) in the contralateral lung $(2,3)$. Although-for resectable lesions-cure could be attained by surgery, the previous contralateral lung resection is a relative (but no absolute) contra-indication for which the risk-benefit ratio of every case should be discussed multidisciplinary. Outcome after post-pneumonectomy lung resection has improved over the last years due to improvement in surveillance techniques [positron emission tomography-computed tomography (PET-CT)] resulting in early diagnosis, careful selection of surgical candidates, advances in anaesthesiology and increasing experience with minimal invasive surgical techniques.

In this paper we review these improvements and summarize the reported outcome of the largest reported single-center series.

\section{Selection of surgical candidates}

Successful long-term outcome of additional lung resection after pneumonectomy greatly depends on careful selection of patients which is based on both oncological as well as functional assessment $(2,4)$. Oncological and functional criteria are summarized in Tables 1,2, respectively.

\section{Oncological assessment}

Extent of the lung tumor determines the long-term benefit of this high-risk surgery. Tumor size and location are evaluated with chest CT. For all patients, PET-CT is recommended and shows the likelihood of malignancy of the lung tumor, mediastinal lymphadenopathies, and distant metastases. Brain CT or magnetic resonance imaging (MRI) allows exclusion of intracranial metastases for lung cancer patients.

Mediastinal lymph nodes can be biopsied with endobronchial ultrasound (EBUS)-guided fine-needle aspiration (FNA). Cervical mediastinoscopy is more challenging due to the previous pneumonectomy with tracheal/mediastinal shift and radiation therapy. Previous $\mathrm{N} 2$ disease precludes surgery due to the anticipated inferior long-term outcome (5).

Tissue diagnosis of the tumor with transthoracic FNA, bronchoscopy guided biopsy or lavage is not mandatory for surgical resection but is useful to differentiate between a metastatic or metachronous tumor. A second primary tumor after pneumonectomy for non-small cell lung cancer (NSCLC) is more likely when the cell type of the lesions is different and the time interval between the lesions is more than 2 years (6). Surgical resection of a metastatic tumor is associated with inferior long-term outcome compared to a metachronous tumor (7-9).

Only patients with a small second primary stage $\mathrm{Ia} / \mathrm{Ib}$ NSCLC or an isolated and small metastatic contralateral NSCLC tumor should be considered for limited resection.

^ ORCID of Jan Van Slambrouck: 0000-0002-7069-1535; ORCID of Laurens J. Ceulemans: 0000-0002-4261-7100 
Table 1 Oncological work-up and criteria

Chest CT: evaluation of tumor size and location

Bronchoscopic or transthoracic tumor biopsy: tissue diagnosis

PET/CT: exclusion of mediastinal lymphadenopathies and distant metastases

Brain CT or MRI: exclusion of intracranial metastases

EBUS or cervical mediastinoscopy: assessment of mediastinal lymph nodes

Sublobar resection (or middle lobectomy) with 1-cm margins should be achievable

Second primary stage I NSCLC (ideal candidates)

Isolated metastatic contralateral NSCLC (inferior outcome)

Table 2 Functional tests and criteria

Spirometry: postoperative predicted FEV1 and DLCO $\geq 40 \%$

Cycle ergometer test: peak oxygen consumption $\geq 10 \mathrm{~mL} / \mathrm{kg} / \mathrm{min}$ or $\geq 35 \%$ (borderline cases)

Cardiac ultrasound: exclusion of pulmonary hypertension or right heart failure

History of right pneumonectomy results in decreased functional capacity versus left pneumonectomy

\section{Functional assessment}

The cardiopulmonary reserve of post-pneumonectomy patients determines the risk for postoperative complications, mortality and quality of life. An acceptable surgical risk is indicated by a predicted postoperative FEV1 and DLCO higher than $40 \%$ of the predicted value, and for borderline cases a peak oxygen consumption higher than $10 \mathrm{~mL} / \mathrm{kg} / \mathrm{min}$ or $35 \%$ of the predicted value should be safeguarded.

Pneumonectomy strongly reduces the pulmonary vascular bed and predisposes for pulmonary hypertension and right heart failure. Preoperative cardiac ultrasound is mandatory to exclude pre-existing pulmonary hypertension or right heart failure which are contra-indications for additional lung resection. It is obvious that-based on an anatomic and physiologic difference in perfusion of $55 \%$ versus $45 \%$ for the right versus left lung-a previous right pneumonectomy entails a larger risk for functional impairment following additional post-pneumonectomy lung resections.

\section{Anaesthesiologic technique}

Anaesthesiologic management for additional lung resection after previous pneumonectomy includes the choice of a perioperative ventilation strategy, perioperative patient monitoring and postoperative care. During surgery, pulmonary gas exchange is monitored with pulse oximetry and capnography. An arterial line ensures hemodynamic monitoring and allows for serial blood gas analyses $(2,4)$.

Since the patient only has one lung, the resection has to be performed while the lung is still ventilating. Finding the right balance between adequate surgical access and maintaining pulmonary gas exchange requires collaboration between the anesthesiologist and the surgeon. The choice of ventilation strategy depends on the surgical approach, location of the tumor, anatomy of the tracheobronchial tree and respiratory functional reserve capacity of the patient (10).

The use of the one-lung-protective ventilation principles cannot be underestimated. Limiting tidal volume to or less than $6 \mathrm{~mL}$ per ideal body weight with positive-endexpiratory pressure of at least $5 \mathrm{cmH}_{2} \mathrm{O}$ and intermittent lung recruitment reduces acute lung injury and improves outcome $(2,7,11,12)$.

For open resections via thoracotomy or sternotomy, low tidal ventilation and short hyperventilation followed by intermittent apnea maintains the operative field (2). For video-assisted thoracic surgery (VATS) ventilation strategies are more challenging. However, allowing minimally invasive lung resection enables enhanced recovery of the patient. Strategies that were reported included highfrequency jet ventilation and selective lobar bronchial blockade. High-frequency jet ventilation is a continuous 
positive airway pressure applied to a bronchopulmonary segment during VATS $(13,14)$. Selective lobar bronchial blockade is achieved with a bronchial blocker $(15,16)$, or double-lumen tube $(10,17)$. These strategies can also be used for open procedures that are technically challenging in order to reduce manipulation and injury to the lung tissue. For peripheral tumors intermittent apnea or standard ventilation with intrapleural $\mathrm{CO} 2$-insufflation can provide sufficient thoracoscopic access $(2,16)$. Recently, also nonintubated (NI) VATS has been proposed to be a safe and feasible technique for thoracic surgery with the potential advantage of reducing postoperative complication rate, hospital stay, and chest pain (18). For these reasons, NIVATS could be considered in limited wedge resection post-pneumonectomy.

In cases where pulmonary gas exchange cannot be guaranteed with ventilation of the remaining lung, extracorporeal membrane oxygenation and cardiopulmonary bypass are available (2). These strategies are rarely necessary (5) and have only been discussed in a few cases $(8,19,20)$. Advantages are creation of an optimal surgical field and the possibility of immediate postoperative extubation. Risks are vascular/cardiac injury due to cannulation, bleeding due to induced coagulopathy and thrombosis due to extracorporeal blood circulation.

Enhanced postoperative recovery is ensured by postoperative pain control, early ambulation, and chest physiotherapy. An epidural catheter can facilitate pain management and reduce the need for opioids. This strategy aims to improve bronchial clearance and ventilation and reduces the incidence of atelectasis or postoperative pneumonia $(2,4)$.

\section{Surgical technique}

The approach and extent of additional lung resection are determined by the tumor location, depth and size. Sublobar resection is considered a safe and effective alternative for high-risk patients with a first primary stage I NSCLC (21). Similarly, a sublobar resection with a minimal margin of $1 \mathrm{~cm}$ has the best risk-benefit ratio after pneumonectomy. Single wedge resection of a peripheral lesion is associated with the best early and long-term outcome for a minimal risk. For more central lesions, segmentectomy and right middle lobectomy can be considered. For every lung resection an extended lymph node dissection should be performed if possible.

Historically, the open approach was routinely performed via median sternotomy (anteromedial tumor), lateral thoracotomy (central and posterior tumors) or musclesparing thoracotomy (peripheral tumors). Today VATS has become standard of care for oncologic resection of NSCLC. With modified ventilation strategies of these singlelung patients, single up to three-port VATS thoracoscopic additional lung resection is feasible and safe $(13,15-17,22,23)$.

Recent techniques like pre-operative three-dimensional reconstruction and per-operative indocyanine-green injection might increase the accuracy of limited resections as required post-pneumonectomy $(22,24)$.

\section{Experience and outcome for lung resection after pneumonectomy for NSCLC}

Experience and outcome for patients that underwent additional lung resection after pneumonectomy is limited. We retrieved ten retrospective cohort studies from the literature reporting on lung resection of metachronous or metastatic NSCLC in the residual lung accounting for a total of 166 patients. The reported population, intervention and outcomes of the papers are outlined in Table 3. The lung resections were performed between 1962 and 2012. All reported procedures were performed with an open approach (sternotomy/thoracotomy), however in the most recent series by Ayub et al. (63 patients) the type of approach was not mentioned (9). In the majority of cases, limited resections (wedge/segmentectomy) were performed and only 13 patients underwent lobectomy.

The earliest cohort studies-representing 47 patientsproved feasibility of lung resection for contralateral NSCLC after pneumonectomy. The authors reported an acceptable postoperative complication rate and an overall limited 30-day mortality of $8.5 \%$ (4/47) after wedge resection or segmentectomy for small lesions in carefully selected patients (25-29).

More recent cohort studies confirmed earlier findings with promising 1 -month mortality and 5 -year overall survival up to $44 \%(5,7,8)$. Patients undergoing a single wedge excision had less respiratory complications, lower 1-month mortality and improved 5-year survival (7). Patients that underwent surgery for metachronous disease had better 5 -year survival over patients with resection for metastatic disease $(7,8)$. Patients that underwent surgery less than 12 months after pneumonectomy had worse longterm survival compared to patients that underwent surgery after a longer interval (5). Patients that underwent surgery for N0-1 disease had better long-term survival than patients 
Table 3 Single center case series of lung resection after pneumonectomy

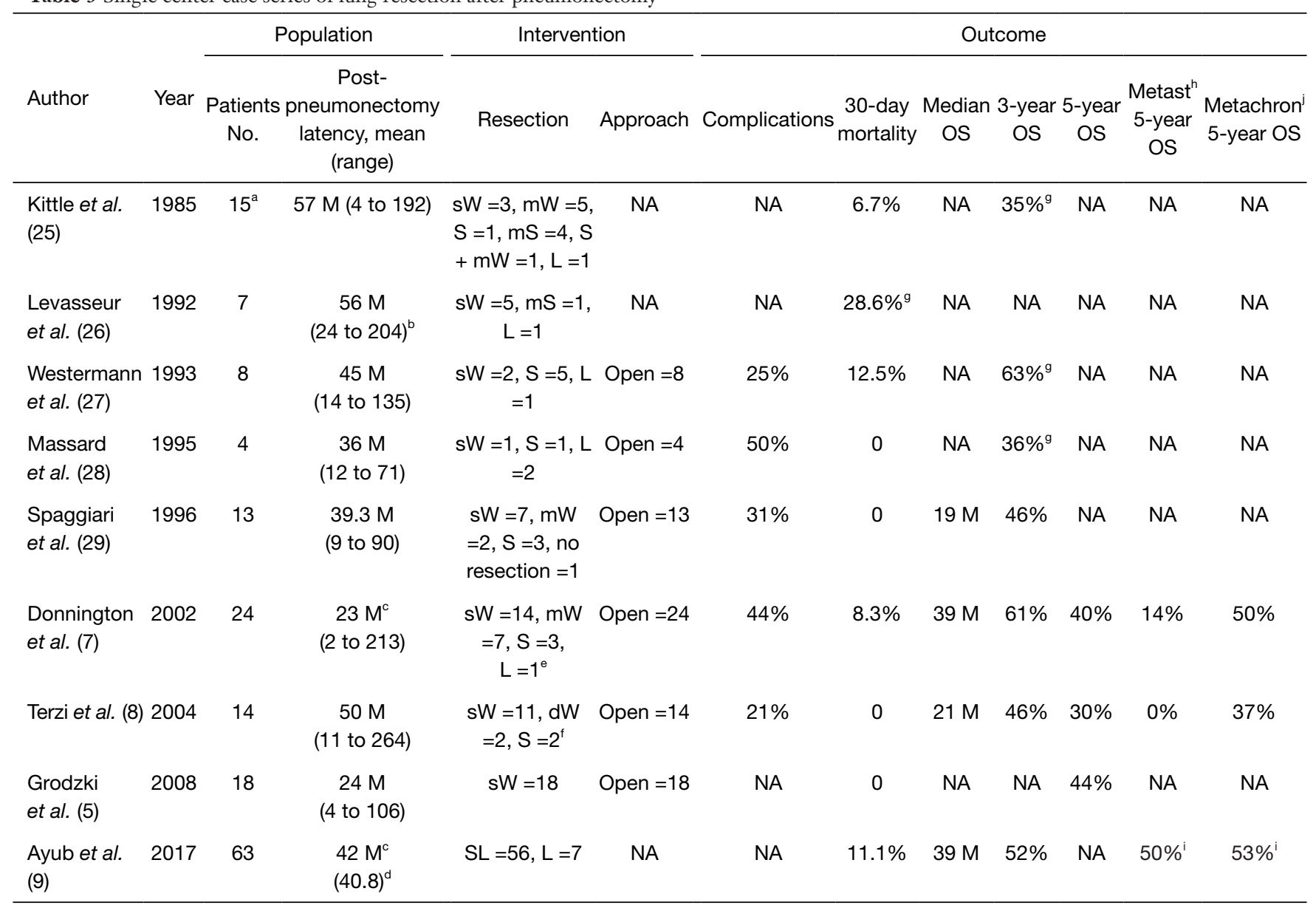

${ }^{a}$, pneumonectomy not for lung cancer in two patients; ${ }^{b}$, adapted from Asai et al. (2); ${ }^{c}$, median; ${ }^{d}$, standard deviation; ${ }^{e}$, one patient underwent sW and $\mathrm{mW} ;{ }^{\mathrm{f}}$, one patient underwent two times sW; ${ }^{\text {, }}$, adapted from Ayub et al. (9); ${ }^{\text {, }}$, metastatic; only considering the cases with isolated metastasis of first contralateral NSCLC; ${ }^{i}$, 3-year overall survival; ${ }^{j}$, metachronous; only considering the cases with second primary contralateral NSCLC. OS, overall survival; NA, not available; sW, single wedge; mW, multiple wedge; S, segment; mS, multiple segments; SL, sublobar; L, lobar; M, months.

after surgery for $\mathrm{N} 2$ disease $(5,30)$.

Most recently a large retrospective cohort study reported data on 170 patients with contralateral NSCLC after pneumonectomy, of which 63 underwent lung resection (9). Patients with shorter post-pneumonectomy latency, tumor size of $2 \mathrm{~cm}$ or smaller and earlier stage (I/II) were more likely to undergo lung resection. Improved 3-year survival was reported after sublobar resection (55\%) compared to lobar resection (29\%). Reported survival rates were higher for metachronous disease compared to metastatic disease. From a functional point of view, the patient should be informed that his/her performance status will further decrease after additional lung resection, as confirmed in a series of 18 patients by Grodzki et al. (5). Despite the high risk for development of pulmonary hypertension and right heart failure, these complications were not specifically reported after additional lung resection.

In most cases additional lung resection is not feasible due to limited pulmonary reserve, comorbidities, tumorrelated and surgery-related difficulties. Stereotactic body radiation therapy (SBRT) is another treatment modality that can provide local control for NSCLC in the postpneumonectomy patient $(2,4,31,32)$. SBRT for medically inoperable patients with primary peripheral early stage NSCLC provides a 3 -year local control rate higher than $90 \%$ and low radiation-associated toxicity (33). Despite earlier concerns, SBRT for primary central NSCLC tumors has also been proven safe $(34,35)$. 
Experience with SBRT for contralateral NSCLC after pneumonectomy is limited. A review of the series that reported data on SBRT after pneumonectomy reported a mean 1-year overall survival and 2-year local control rate of $80.6 \%$ and $89.4 \%$, respectively. Significant pulmonary radiation toxicity was found in $13.2 \%$ of cases (31).

These favorable results support the choice for SBRT in patients suffering from contralateral NSCLC after pneumonectomy that are considered inoperable or refuse surgery. Head-to-head comparisons between additional lung resection and SBRT are not available. The question whether surgery is superior to radiotherapy for these high-risk patients remains unanswered. In clinical practice, the choice for local control with lung resection or SBRT should be evaluated by a multidisciplinary team of thoracic surgeons, radiation oncologists, radiologists and medical oncologists.

\section{Conclusions}

For selected patients with sufficient cardiorespiratory reserve capacity lung resection post-pneumonectomy is a safe and feasible treatment option. Adequate preoperative surveillance imaging, improvement of lung protective anaesthetic management as well as less invasive and increased precision surgical techniques have led to improved outcome.

Based on the retrospectively collected data, limited sublobar lung resections provide the best risk-benefit ratio. Wedge resection of peripheral small sized $(\leq 2 \mathrm{~cm})$, N0-1 contralateral metachronous NSCLC after pneumonectomy appears to be associated with the best long-term outcome. Segmentectomy or right middle lobectomy can be considered for central NSCLC tumor lesions. In selected patients a 3-year survival rate of $50 \%$ can be attained for sublobar resection. Reported survival rates were higher for metachronous disease compared to metastatic disease. In case of inoperability, SBRT is an adequate alternative.

\section{Acknowledgments}

We thank Prof. Dr. Paul De Leyn for his teaching and advise.

Funding: None.

\section{Footnote}

Provenance and Peer Review: This article was commissioned by the Guest Editors (Lorenzo Spaggiari and Luca
Bertolaccini) for the series "The Role of Pneumonectomy in Thoracic Surgery in The Third Millennium" published in Shanghai Chest. The article did not undergo external peer review.

Conflicts of Interest: Both authors have completed the ICMJE uniform disclosure form (available at http:// dx.doi.org/10.21037/shc-20-75). The series "The Role of Pneumonectomy in Thoracic Surgery in The Third Millennium" was commissioned by the editorial office without any funding or sponsorship. The authors have no other conflicts of interest to declare.

Ethical Statement: The authors are accountable for all aspects of the work in ensuring that questions related to the accuracy or integrity of any part of the work are appropriately investigated and resolved.

Open Access Statement: This is an Open Access article distributed in accordance with the Creative Commons Attribution-NonCommercial-NoDerivs 4.0 International License (CC BY-NC-ND 4.0), which permits the noncommercial replication and distribution of the article with the strict proviso that no changes or edits are made and the original work is properly cited (including links to both the formal publication through the relevant DOI and the license). See: https://creativecommons.org/licenses/by-nc-nd/4.0/.

\section{References}

1. Dhanasopon AP, Salazar MC, Hoag JR, et al. Fate of pneumonectomy patients variably captures by nonsmall cell lung cancer staging system. Ann Thorac Surg 2017;104:1829-36.

2. Asai M, Scott WJ. Lung Resection in the Postpneumonectomy Patient. Thoracic Surgery Clinics 2018;28:19-25.

3. Bhaskarla A, Tang PC, Mashtare T, et al. Analysis of second primary lung cancers in the SEER database. J Surg Res 2010;162:1-6.

4. Mercier O, de Perrot M, Keshavjee S. Pulmonary resection after pneumonectomy. Thorac Surg Clin 2014;24:433-9.

5. Grodzki T, Alchimowicz J, Kozak A, et al. Additional pulmonary resections after pneumonectomy: actual longterm survival and functional results. Eur J Cardiothorac Surg 2008;34:493-8.

6. Martini N, Melamed MR. Multiple primary lung cancers. J Thorac Cardiovasc Surg 1975;70:606-12. 
7. Donington JS, Miller DL, Rowland CC, et al. Subsequent pulmonary resection for bronchogenic carcinoma after pneumonectomy. Ann Thorac Surg 2002;74:154-8.

8. Terzi A, Lonardoni A, Scanagatta $\mathrm{P}$, et al. Lung resection for bronchogenic carcinoma after pneumonectomy: a safe and worthwhile procedure. Eur J Cardiothorac Surg 2004;25:456-9.

9. Ayub A, Rehmani SS, Al-Ayoubi AM, et al. Pulmonary Resection for Second Lung Cancer After Pneumonectomy: A Population-Based Study. Ann Thorac Surg 2017;104:1131-7.

10. Ng JM, Hartigan PM. Selective Lobar Bronchial Blockade following Contralateral Pneumonectomy. Anesthesiology 2003;98:268-70.

11. Lohser J, Slinger P. Lung Injury After One-Lung Ventilation: A Review of the Pathophysiologic Mechanisms Affecting the Ventilated and the Collapsed Lung. Anesthesia \& Analgesia 2015;121:302-18.

12. Liu Z, Liu X, Huang Y, Zhao J. Intraoperative mechanical ventilation strategies in patients undergoing one-lung ventilation: a meta-analysis. SpringerPlus 2016;5:1251.

13. Lohser J, McLean SR. Thoracoscopic Wedge Resection of the Lung Using High-Frequency Jet Ventilation in a Postpneumonectomy Patient. A \& A Case Reports 2013;1:39-41.

14. Ikegaki J, Katoh H. A Single Lobal Inflation Technique Using Bronchofiberoptic Jet Ventilation During VideoAssisted Thoracoscopic Surgery for Bullae. Anesthesia \& Analgesia 2002;95:1462.

15. Fukui Y, Kohno T, Fujimori S, et al. Three-Port Thoracoscopic Middle Lobectomy in a Patient After Left Pneumonectomy. Ann Thorac Surg 2015;99:1422-5.

16. Goto H, Mun M, Mori S, et al. Thoracoscopic partial lung resection following pneumonectomy: a report of three cases. J Cardiothorac Surg 2019;14:183.

17. Gu Y, Duan R, Lv X, Song J. Airway Management of the Right Anterior Segmentectomy through Uniportal video-assisted thoracoscopic surgery (VATS) after left pneumonectomy by an adapted double-lumen endobronchial tube (DLT): a case report. BMC Anesthesiol 2019;19:82.

18. Zhang K, Hui-Guo C, Wei-Bin W, et al. Non-intubated video-assisted thoracoscopic surgery vs. intubated videoassisted thoracoscopic surgery for thoracic disease: a systematic review and meta-analysis of 1684 cases. J Thorac Dis 2019;11:3556-68.

19. Spaggiari L, Rusca M, Carbognani P, et al. Segmentectomy on a Single Lung by Femorofemoral Cardiopulmonary
Bypass. Ann Thorac Surg 1997;64:1519.

20. Gillon SA, Toufektzian L, Harrison-Phipps K, et al. Perioperative Extracorporeal Membrane Oxygenation to Facilitate Lung Resection After Contralateral Pneumonectomy. The Annals of Thoracic Surgery 2016;101:e71-3.

21. Klapper JA, Hittinger SA, Denlinger CE. Alternatives to Lobectomy for High-Risk Patients With EarlyStage Non-Small Cell Lung Cancer. Ann Thorac Surg 2017;103:1330-9.

22. Zhang C, Lin H, Fu R, et al. Application of indocyanine green fluorescence for precision sublobar resection. Thorac Cancer 2019;10:624-30.

23. Walsh K, Park B, Amar D. Segmental Lung Isolation in a Postpneumonectomy Patient Undergoing Contralateral Lung Resection. J Cardiothorac Vasc Anesth 2017;31:1048-50.

24. Saji H, Inoue T, Kato Y, et al. Virtual segmentectomy based on high-quality three-dimensional lung modelling from computed tomography images. Interact Cardiovasc Thorac Surg 2013;17:227-32.

25. Kittle CF, Faber LP, Jensik RJ, et al. Pulmonary Resection in Patients after Pneumonectomy. Ann Thorac Surg 1985;40:294-9.

26. Levasseur P, Regnard JF, Icard P, et al. Cancer surgery on a single residual lung. Eur J Cardiothorac Surg 1992;6:63940; discussion 641.

27. Westermann CJJ, van Swieten HA, de la Rivière AB, et al. Pulmonary resection after pneumonectomy in patients with bronchogenic carcinoma. J Thorac Cardiovasc Surg 1993;106:868-74.

28. Massard G, Wihlm J-M, Morand G. Surgical management for metachronous bronchogenic cancer occurring after pneumonectomy. J Thorac Cardiovasc Surg 1995;109:597-600.

29. Spaggiari L, Grunenwald D, Girard P, et al. Cancer Resection on the Residual Lung After Pneumonectomy for Bronchogenic Carcinoma. Ann Thorac Surg 1996;62:1598-602.

30. Toufektzian L, Patris V, Potaris K, et al. Is it safe and worthwhile to perform pulmonary resection after contralateral pneumonectomy? Interact CardioVasc Thorac Surg 2015;20:265-9.

31. Arifin $\mathrm{AJ}, \mathrm{Al}-\mathrm{Shafa} \mathrm{F}, \mathrm{Chen} \mathrm{H}$, et al. Is lung stereotactic ablative radiotherapy safe after pneumonectomy? - a systematic review. Transl Lung Cancer Res 2020;9:348-53.

32. Ayub A, Rehmani S, Al-Ayoubi AM, et al. Radiation therapy improves survival for unresectable 
postpneumonectomy lung tumors. J Surg Res

2018;227:60-6.

33. Timmerman R, Paulus R, Galvin J, et al. Stereotactic

Body Radiation Therapy for Inoperable Early Stage Lung Cancer. JAMA 2010;303:1070-6.

34. Rowe BP, Boffa DJ, Wilson LD, et al. Stereotactic Body

doi: $10.21037 /$ shc-20-75

Cite this article as: Van Slambrouck J, Ceulemans LJ. Lung resection after pneumonectomy: is it worth the risk? Shanghai Chest 2021;5:22.
Radiotherapy for Central Lung Tumors. Journal of Thoracic Oncology 2012;7:1394-9.

35. Lischalk JW, Malik RM, Collins SP, et al. Stereotactic body radiotherapy (SBRT) for high-risk central pulmonary metastases. Radiation Oncology 2016;11:28. 